\title{
PEGAMENTO E CRESCIMENTO INICIAL DE ENXERTOS DO PESSEGUEIRO 'AURORA-1' EM CLONES DE UMEZEIRO (Prunus mume Sieb. et Zucc.) E 'OKINAWA' [Prunus persica (L.) Batsch] PROPAGADOS POR ESTACAS HERBÁCEAS ${ }^{1}$
}

\author{
NEWTON ALEX MAYER ${ }^{2}$, FERNANDO MENDES PEREIRA ${ }^{3}$, JOSÉ CARLOS BARBOSA $^{4}$
}

\begin{abstract}
RESUMO - O presente estudo teve por objetivo avaliar o pegamento e o crescimento inicial de enxertos do pessegueiro 'Aurora-1' em clones de umezeiro (Prunus mume Sieb. et Zucc.) e 'Okinawa' [Prunus persica (L.) Batsch] propagados por estacas herbáceas. Realizaram-se dois experimentos, adotando-se a enxertia de borbulhia por escudo (março) e borbulhia por escudo modificada (julho). Com os resultados obtidos, pode-se concluir que é viável a realização da enxertia do 'Aurora-1' nos Clones 05; 10 e 15 de umezeiro e no 'Okinawa', tanto em março quanto em julho, com as metodologias utilizadas. O 'Okinawa' induz crescimento mais rápido ao enxerto, de forma que o ponto máximo do comprimento é atingido em tempo menor. Termos para indexação: Enxertia interespecífica, compatibilidade, porta-enxerto.
\end{abstract}

\section{TISSUE UNION AND INITIAL GROWTH OF 'AURORA-1' PEACH BUDS ON MUME CLONES (Prunus mume Sieb. et Zucc.) AND 'OKINAWA’ [Prunus persica (L.) Batsch] PROPAGATED BY HERBACEOUS CUTTINGS}

\begin{abstract}
This study aimed to evaluate the tissue union and initial growth of 'Aurora-1' peach buds on mume clones (Prunus mume Sieb. et Zucc.) and 'Okinawa' [Prunus persica (L.) Batsch] propagated by herbaceous cuttings. Two experiments were carried out, being adopted the chip budding (March) and chip budding modified (July). The results showed that accomplishment of 'Aurora-1' peach bud on mume Clones 05,10 and 15 and 'Okinawa' is viable, in both periods, with the methodologies used. The 'Okinawa' induces faster growth to the bud and the maximum length point is reached in a short time.
\end{abstract}

Index terms: Interespecific bud, compatibility, rootstock.

\section{INTRODUÇÃO}

A qualidade da muda é, sem dúvida, um dos principais fatores a ser observado na implantação adequada de um pomar. Para a avaliação da qualidade das mudas de pessegueiro, alguns aspectos devem ser observados, como: identificação do porta-enxerto e da cultivar-copa, compatibilidade comprovada, resistência ou tolerância do porta-enxerto às principais espécies de fitonematóides, quantidade e distribuição adequadas de raízes, dentre outros.

No Sul do Brasil, os porta-enxertos para pessegueiro são formados a partir de caroços de diversas cultivares de maturação tardia, obtidas nas indústrias conserveiras. Desta forma, os porta-enxertos assim formados apresentam grande variabilidade genética, e sua identidade é desconhecida. As conseqüências desta prática são notáveis nos pomares, como a desuniformidade das plantas, diferenças na reação aos fitonematóides e outras doenças e pragas de solo, além da relação com a doença conhecida por "morte precoce dos pessegueiros" (Fachinello, 2000). Na região Sudeste, a preferência é pelo ‘Okinawa' [Prunus persica (L.) Batsch], cultivar introduzida pelo Instituto Agronômico de Campinas em 1969 (Ojima et al., 1999) e que apresenta resistência aos nematóides do gênero Meloidogyne (Malo, 1967).

Durante muitos anos, os Programas Brasileiros de Melhoramento Genético do Pessegueiro preocuparam-se com as cultivares-copa e deixaram de lado o porta-enxerto (Raseira \& Nakasu, 2002). Segundo estes autores, não existem trabalhos de hibridação no Brasil visando ao melhoramento genético do porta-enxerto, pois é necessário, inicialmente, testar aqueles, locais ou introduzidos, tanto quanto às características já conhecidas como aquelas que não se dispõe de informação.

Nas décadas de 80 e 90, foram realizados, no Instituto Agronômico de Campinas, estudos com o umezeiro (Prunus mume Sieb. et Zucc.) como porta-enxerto para pessegueiro, onde foram constatados a compatibilidade da enxertia, aumentos na massa, teor de sólidos solúveis e porcentagem de vermelho na película dos frutos, além da redução no vigor das plantas e possibilidade de adensamento dos pomares (Campo Dall'Orto et al., 1992; Campo Dall'Orto et al., 1994). Posteriormente, a compatibilidade da enxertia do umezeiro com nove cultivares de pessegueiro e duas de nectarineira e a redução da altura das mudas em viveiro foram comprovadas em estudo realizado na ESALQ/USP (Nakamura et al., 1999). Hartmann \& Kester (1978) citam que a enxertia de plantas pertencentes a um mesmo gênero pode apresentar amplas possibilidades de sucesso em alguns casos, entretanto, em outros não. Dentro do gênero Prunus, os autores citam que cultivares de amendoeira $(P$. amygdalus), damasqueiro ( $P$. armeniaca), ameixeira européia $(P$. domestica) e ameixeira japonesa ( $P$. salicina), são enxertadas comercialmente usando o pessegueiro (P. persica) como porta-enxerto. Por outro lado, a amendoeira e o damasqueiro são incompatíveis entre si. Segundo estes autores, a compatibilidade entre espécies pode depender também de um clone específico e da posição que a espécie ocupa na combinação (enxerto ou porta-enxerto), pois casos de compatibilidade podem constituir uniões incompatíveis, quando o inverso é realizado.

As pesquisas realizadas no IAC, com o umezeiro, revelaram grande variabilidade genética da espécie em decorrência da propagação por sementes. Iniciaram-se então, a partir de 1998 na FCAV/UNESP, Câmpus de Jaboticabal, estudos com a propagação do umezeiro por estacas herbáceas, onde foram selecionados os Clones 02; 05; 10 e 15 como viáveis para serem propagados por este método (Nachtigal et al., 1999; Mayer et al., 2001; Mayer et al., 2002; Mayer \& Pereira, 2003; Mayer \& Pereira, 2004), sendo que os Clones 05; 10 e 15 apresentam resistência a Meloidogyne javanica (Mayer et al., 2003). Entretanto, nenhum estudo de enxertia foi realizado com estes clones, o que se torna indispensável para o avanço das pesquisas.

O objetivo do presente trabalho foi estudar o pegamento e o crescimento de enxertos do pessegueiro 'Aurora-1' em clones de umezeiro e 'Okinawa' propagados por estacas herbáceas.

\section{MATERIALEMÉTODOS}

Estacas herbáceas dos Clones 05; 10 e 15 de umezeiro e do pessegueiro 'Okinawa' foram enraizadas em câmara de nebulização

\footnotetext{
${ }^{1}$ (Trabalho 138/2004), Recebido: 12/08/2004. Aceito para publicação: 08/04/2005. Apoio Financeiro: FAPESP. Parte da Tese de Doutorado do primeiro autor.

${ }^{2}$ Eng. Agr., Dr. FCAV/UNESP, Depto. de Produção Vegetal - Via de Acesso Prof. Paulo Donato Castellane s/n, CEP 14884-900. Jaboticabal-SP. e-mail: mayersul@yahoo.com.br

${ }^{3}$ Eng. Agr., Dr., Prof. Voluntário do Depto. de Produção Vegetal da FCAV/UNESP, Campus de Jaboticabal-SP. e-mail: fmendes@ fcav.unesp.br

${ }^{4}$ Eng. Agr., Dr., Prof. Titular do Depto. de Ciências Exatas, FCAV/UNESP, Jaboticabal-SP. jcbarbosa@ fcav.unesp.br
} 
intermitente (Mayer et al., 2001), localizada no "Sítio São João" (Taquaritinga-SP), utilizando-se de vermiculita fina como substrato e caixas de madeira $(48 \times 33 \times 9 \mathrm{~cm})$ como contentores. Transcorrido o período de enraizamento, as estacas enraizadas foram classificadas em uma escala visual de notas, objetivando eliminar as inadequadas ao transplantio. As selecionadas foram transplantadas para sacos plásticos (28 x $18 \mathrm{~cm})$ contendo substrato comercial (mistura de cascas de vegetais processadas e enriquecidas, vermiculita expandida e carvão vegetal granulado), com $150 \%$ de capacidade de retenção de água e irrigadas quando necessário. As plantas foram mantidas em viveiro com piso cimentado e coberto com sombrite (50\%) durante todo o período de condução dos dois experimentos.

Foi realizado periodicamente o desbaste de brotações indesejáveis das estacas, procurando mantê-las em haste única e tutoradas com lascas de bambu, objetivando a condução vertical. A fertilização do substrato consistiu de uma adubação com Osmocote ${ }^{\circledR}$ (com 5 a 6 meses de liberação) aos 19 dias após o transplantio, na dose de $6 \mathrm{~g}$ por saco plástico $(\mathrm{N}=15 \% ; \mathrm{P}=10 \% ; \mathrm{K}=10 \% ; \mathrm{Ca}=3,5 \% ; \mathrm{Mg}=1,5 \%$; $\mathrm{S}=3 \%$ + micronutrientes) e de uma aplicação de calcário dolomítico (137\% de PRNT, $45 \%$ de $\mathrm{CaO}$ e $25 \%$ de $\mathrm{MgO}$ ), na dose de 4 a $5 \mathrm{~g}$ por saco plástico, aos 90 dias após o transplante, para suprir necessidades de cálcio e magnésio.

Foram adotadas duas metodologias para a execução da enxertia, em duas épocas diferentes (março e julho de 2002), constituindo dois experimentos distintos, a seguir descritos.

\section{Borbulhia por escudo (março de 2002)}

Aos 130 dias após o transplantio das estacas para os sacos plásticos, foi realizada uma seleção dos porta-enxertos com diâmetro acima de 3,2mm, considerado limite mínimo para a realização da enxertia. Desta forma, 34,94\%, 29,32\%, 38,93\% e 54,36\% das hastes (a $5 \mathrm{~cm}$ acima da estaca original) dos Clones 05; 10; 15 e 'Okinawa', respectivamente, foram selecionadas. Retiraram-se os tutores, e as hastes foram encurtadas para $50 \mathrm{~cm}$, de forma a facilitar a enxertia. Os ramos borbulheiros foram obtidos no dia anterior à enxertia em pomar comercial de pessegueiro cv. Aurora-1 (Taiúva-SP), retirando-se apenas o limbo foliar.

A enxertia foi realizada na haste, aproximadamente $5 \mathrm{~cm}$ acima da estaca que deu origem à planta. Foi adotada a enxertia de borbulhia por escudo, conforme Hartmann \& Kester (1978). Para tanto, inicialmente, foi realizado um corte transversal inclinado em $45^{\circ}$ no porta-enxerto, de cima para baixo, penetrando aproximadamente 1/4 do diâmetro, que formou um pequeno encaixe para receber a borbulha. Outro corte foi realizado, iniciando-o a $2,5 \mathrm{~cm}$ acima deste, descendente até o corte transversal, retirando-se a porção de córtex e lenho. Cortes semelhantes foram realizados no ramo borbulheiro, de forma a coincidir o tamanho da borbulha com a abertura no porta-enxerto. $\mathrm{O}$ amarrio foi feito com fita plástica, deixando-se a gema e o pecíolo descobertos. O manejo seguinte consistiu na eliminação parcial das copas dos porta-enxertos a $10 \mathrm{~cm}$ acima do ponto de enxertia (aos 14 dias) e, posteriormente (aos 40 dias), da eliminação completa da parte superior do porta-enxerto. Realizaramse, também, desbrotas semanais dos porta-enxertos, objetivando o pegamento do enxerto.

$\mathrm{O}$ experimento foi conduzido em delineamento experimental inteiramente casualizado, com 4 tratamentos (porta-enxertos: Clones 05; 10 e 15 de umezeiro e cv. Okinawa) e 5 repetições de 20 plantas. As variáveis analisadas foram: comprimento de enxertos (mensurado com fita métrica) aos 30; 40; 50; 60; 70; 80; 90 e 180 dias após a enxertia; diâmetro do enxerto a $5 \mathrm{~cm}$ acima do ponto de enxertia (mensurado com paquímetro digital) aos 90 e 180 dias após a enxertia; porcentagem de pegamento dos enxertos e porcentagem de porta-enxertos mortos, aos 180 dias após a enxertia. As variáveis expressas em porcentagem foram transformadas em arco-seno $\sqrt{P / 100}$, onde $P$ é o valor observado da porcentagem, e as demais variáveis não sofreram transformação. Os dados foram submetidos à análise de variância, pelo teste F, e as médias foram comparadas pelo teste de Tukey, a 5\% de probabilidade. Para estudar o comprimento do enxerto em função do tempo, utilizou-se de uma função logística dada pela equação $y \frac{a}{1 e^{k x x_{c}}}$, onde $y=$ comprimento; $a=$ máximo ajustado; $e=2,7182 ; k=$ taxa de crescimento; $x=$ tempo; $x_{c}=$ ponto de inflexão da curva. Para o cálculo do número de dias onde o ponto máximo foi atingido, consideraram-se desprezíveis as diferenças menores que 0,1 .

\section{Borbulhia por escudo modificada (julho de 2002)}

Os porta-enxertos que não apresentavam diâmetro adequado à realização da enxertia em março de 2002, foram conduzidos até o mês de julho (8,5 meses após o transplantio), ocasião em que foi realizada nova seleção, utilizando-se como critério do diâmetro mínimo de 3,2mm. As porcentagens de plantas selecionadas e enxertadas foram $71,62 \%$, $66,28 \%, 58,54 \%$ e 77,67\%, para o Clone 05, Clone 10, Clone 15e 'Okinawa', respectivamente.

Os ramos borbulheiros foram obtidos de modo semelhante ao experimento anterior. A enxertia foi realizada no dia 16 de julho de $2002 \mathrm{e}$ constou da retirada do pecíolo da borbulha rente à gema, realização de um único corte descendente no porta-enxerto, sem encaixe, e amarrio da borbulha, cobrindo-se totalmente a gema. Desta forma, a fixação da borbulha ao porta-enxerto foi feita somente com a fita plástica, de adequada elasticidade. Para o amarrio, cobriu-se inicialmente a gema com cuidado para não danificá-la e, em seguida, esticando-se a fita, envolveu-se toda a área de união das partes. A fita plástica foi retirada somente aos 28 dias após a enxertia com lâmina de barbear, ocasião em que a borbulha já estava perfeitamente cicatrizada ao porta-enxerto. Aos 36 dias após a enxertia, foi feita a eliminação parcial da copa do portaenxerto com um corte a $10 \mathrm{~cm}$ acima da enxertia e, aos 60 dias, a eliminação completa, com corte rente acima do ponto de emissão do enxerto.

O delineamento experimental adotado foi o inteiramente casualizado, com 4 tratamentos (porta-enxertos) e 5 repetições de 20 plantas. As variáveis analisadas aos 200 dias após a enxertia foram: comprimento do enxerto, diâmetro do enxerto a $5 \mathrm{~cm}$ acima do ponto de enxertia, porcentagem de pegamento dos enxertos e porcentagem de porta-enxertos mortos.

\section{RESULTADOS E DISCUSSÃO}

\section{Borbulhia por escudo (março de 2002)}

Os valores referentes ao comprimento dos enxertos são apresentados na Tabela 1. Observa-se que, em todas as avaliações realizadas, o porta-enxerto 'Okinawa' induziu maior vigor ao enxerto, traduzindo-se em maior comprimento da brotação da cv. Aurora-1 em relação aos clones de umezeiro. Estes resultados concordam com Nakamura et al. (1999), que constataram que a altura de mudas de 11 cultivares de pessegueiros e nectarineiras enxertadas em umezeiro foi menor do que as enxertadas em Okinawa, aos 150 dias após a enxertia. Em condições de campo, após três anos de observações, Campo Dall'Orto et al. (1992) observaram variabilidade no comportamento de 27 cultivarescopa de pessegueiros e nectarineiras, quando enxertadas na seleção de umezeiro 'Iacume' (IAC-3). Entretanto, quando as cultivares foram classificadas em uma escala de comportamento, a cultivar Aurora-1 foi enquadrada na melhor nota, com redução do porte das plantas de $2 / 3$ a $1 / 2$, em relação às enxertadas em 'Okinawa'. No presente experimento, tomando-se como referência o comprimento dos enxertos das plantas enxertadas em 'Okinawa', aos 180 dias, observam-se reduções de 37,3\%, $23,6 \%$ e $27,5 \%$ no comprimento dos enxertos, quando enxertadas nos Clones 05; 10 e 15 de umezeiro, respectivamente. Entre os clones de umezeiro, as diferenças estatísticas só foram observadas aos 60 e 80 dias após a enxertia, onde o Clone 05 induziu menor crescimento da cv. Aurora-1, quando comparada às mudas enxertadas no Clone 10.

Os valores referentes ao diâmetro do enxerto (Tabela 2) evidenciam diferenças estatísticas somente aos 90 dias após a enxertia, sendo que as mudas enxertadas em 'Okinawa' apresentaram diâmetro maior em relação aos clones de umezeiro. Entretanto, aos 180 dias, essas diferenças não foram mais detectadas. Para esta variável, Nakamura et 
TABELA 1 - Comprimento de enxertos $(\mathrm{cm})$ do pessegueiro cv. Aurora-1 em porta-enxertos dos Clones 05, 10 e 15 de umezeiro e 'Okinawa', em diferentes períodos, após a realização da enxertia de borbulhia por escudo (março). Taquaritinga-SP, setembro de 2002.

\begin{tabular}{|c|c|c|c|c|c|c|c|c|}
\hline \multirow[b]{2}{*}{ Clone } & \multicolumn{8}{|c|}{ Comprimento de enxertos $(\mathrm{cm})$ nas diferentes avaliações (dias) após a enxertia } \\
\hline & 30 & 40 & 50 & 60 & 70 & 80 & 90 & 180 \\
\hline Clone 05 & $0,17 \mathrm{~b}$ & $0,52 \mathrm{~b}$ & $2,62 \mathrm{~b}$ & $7,42 \mathrm{c}$ & $15,34 \mathrm{~b}$ & $20,19 \mathrm{c}$ & $22,58 \mathrm{~b}$ & $25,43 \mathrm{~b}$ \\
\hline Clone 10 & $0,24 \mathrm{~b}$ & $1,48 \mathrm{~b}$ & $6,89 \mathrm{~b}$ & $15,45 \mathrm{~b}$ & $23,69 \mathrm{~b}$ & $28,77 \mathrm{~b}$ & $29,99 \mathrm{~b}$ & $30,96 \mathrm{~b}$ \\
\hline Clone 15 & $0,27 \mathrm{~b}$ & $0,94 \mathrm{~b}$ & $4,19 \mathrm{~b}$ & $11,00 \mathrm{bc}$ & $19,23 \mathrm{~b}$ & $25,35 \mathrm{bc}$ & $27,72 b$ & $29,40 \mathrm{~b}$ \\
\hline Okinawa & $1,70 \mathrm{a}$ & $10,68 \mathrm{a}$ & $23,18 \mathrm{a}$ & $33,71 \mathrm{a}$ & $38,81 \mathrm{a}$ & $40,80 \mathrm{a}$ & $41,11 \mathrm{a}$ & $40,54 \mathrm{a}$ \\
\hline D.M.S. & 0,3322 & 1,7744 & 4,3677 & 7,0543 & 8,9469 & 8,4059 & 7,6818 & 6,4356 \\
\hline $\mathrm{F}$ & 80,61 ** & $123,52 * *$ & $77,19^{* *}$ & $44,97 * *$ & $21,63 * *$ & $17,80^{* *}$ & $16,97 * *$ & $16,25^{* *}$ \\
\hline CV $(\%)$ & 30,93 & 28,78 & 26,16 & 23,06 & 20,35 & 16,13 & 13,97 & 11,25 \\
\hline
\end{tabular}

Médias seguidas por letras distintas, na mesma coluna, diferem entre si, pelo teste de Tukey. ** significativo ao nível de $1 \%$ de probabilidade.

TABELA 2 - Diâmetro do enxerto (mm) do pessegueiro cv. Aurora-1 a $5 \mathrm{~cm}$ acima do ponto de enxertia aos 90 e 180 dias, porcentagem de pegamento de enxertos e de porta-enxertos mortos aos 180 dias após a enxertia de borbulhia por escudo (março), utilizando-se de diferentes portaenxertos. Taquaritinga-SP, setembro de 2002.

\begin{tabular}{|c|c|c|c|c|}
\hline \multirow[b]{2}{*}{ Clone } & \multicolumn{2}{|c|}{ Diâmetro do enxerto (mm) } & \multirow{2}{*}{$\begin{array}{c}\% \text { de pegamento } \\
\text { de enxertos }\end{array}$} & \multirow{2}{*}{$\begin{array}{c}\% \text { de porta-enxertos } \\
\text { mortos }\end{array}$} \\
\hline & 90 dias & 180 dias & & \\
\hline Clone 05 & $2,63 \mathrm{~b}$ & $3,74 \mathrm{a}$ & $54,55 \mathrm{~b}$ & $45,45 \mathrm{a}$ \\
\hline Clone 10 & $2,81 \mathrm{~b}$ & 3,88 a & $66,00 \mathrm{~b}$ & $32,00 \mathrm{a}$ \\
\hline Clone 15 & $2,81 \mathrm{~b}$ & 3,98 a & $58,00 \mathrm{~b}$ & $37,00 \mathrm{a}$ \\
\hline Okinawa & 3,66 a & $4,15 \mathrm{a}$ & $96,00 \mathrm{a}$ & $3,00 \mathrm{~b}$ \\
\hline D.M.S & 0,5192 & 0,4762 & $11,4771^{1}$ & $11,5141^{1}$ \\
\hline $\mathrm{F}$ & $12,91 * *$ & $2,11^{\mathrm{ns}}$ & $27,27 * *$ & $29,63 * *$ \\
\hline CV $(\%)$ & 9,62 & 6,68 & 10,95 & 20,89 \\
\hline
\end{tabular}

Médias seguidas por letras distintas, na mesma coluna, diferem entre si, pelo teste de Tukey. ${ }^{1}$ diferença mínima significativa obtida para os valores transformados; ${ }^{\text {ns }}$ não significativo; ** significativo ao nível de $1 \%$ de probabilidade.

\section{al. (1999) não observaram diferenças entre o umezeiro e 'Okinawa'.}

Com relação à porcentagem de pegamento de enxertos (Tabela

2), verifica-se que houve diferença entre os porta-enxertos, sendo que as mudas enxertadas em 'Okinawa' apresentaram maior pegamento $(96 \%) \mathrm{em}$ relação aos clones de umezeiro, que apresentaram valores entre $54,55 \%$ e $66 \%$. Estes resultados não concordam com Nakamura et al. (1999), que não observaram diferenças no pegamento de enxertos entre o umezeiro e 'Okinawa'. Para estes autores, a porcentagem de pegamento em umezeiro foi superior a 70\% em todas as cultivares-copa testadas. Campo Dall'Orto et al. (1992), realizando enxertia de borbulhia de "chapinha" em três pontos na seleção de umezeiro 'Iacume' (IAC-3), verificaram porcentagens de pegamento superiores a $80 \%$. No presente trabalho, a menor porcentagem de pegamento de enxertos, comparativamente aos apresentados naqueles trabalhos, pode ser explicada com o menor diâmetro dos clones de umezeiro (que variou de 3,2 a 4,5mm), em relação ao adotado por aqueles autores (em torno de $1 \mathrm{~cm}$ ), o que desfavoreceu o pegamento dos enxertos. Desta forma, a realização dos cortes na enxertia contribuiu para as elevadas porcentagens de porta-enxertos mortos (variação de $32 \%$ a $45,45 \%$ ), o que influenciou na porcentagem de pegamento dos enxertos (Tabela 2). Desconsiderando-se as porcentagens de porta-enxertos mortos, é possível constatar valores de pegamento de enxertos superiores a $95 \%$.

$\mathrm{O}$ crescimento dos enxertos em comprimento é ilustrado na Figura 1. A função logística apresentou um grau de ajuste superior a $99,7 \%$ para todos os porta-enxertos estudados. Com o ajuste das curvas, foi possível identificar que o porta-enxerto 'Okinawa', que apresentou o menor valor de $x c(48,16279$, que é tempo necessário para que o enxerto atinja a metade do crescimento máximo), imprimiu crescimento mais rápido ao enxerto, de forma que o comprimento atingiu o ponto máximo em tempo menor (91 dias). Entre os clones de umezeiro, os pontos máximos foram atingidos aos 113; 106 e 111 dias, respectivamente, para os Clones $05 ; 10$ e 15 . Na prática, esses valores representam o momento ideal em que as mudas deveriam ser transplantadas para o local definitivo do pomar, pois o crescimento do enxerto em condições de viveiro já está estabelecido.

\section{Borbulhia por escudo modificada (julho de 2002)}

Os valores obtidos nas variáveis avaliadas neste experimento, em fevereiro de 2003, são apresentados na Tabela 3. Os resultados observados para o comprimento de enxertos diferem do primeiro experimento, pois os porta-enxertos 'Okinawa', Clone 10 e Clone 15 não apresentaram diferenças entre si, entretanto todos foram superiores ao Clone 05. Este fato pode ser explicado pelo longo período (200 dias) em que as plantas foram mantidas no viveiro e à época do ano (verão estação das águas), o que pode ter dificultado o crescimento das plantas enxertadas em 'Okinawa', em função da limitação de espaço do sistema radicular no recipiente, não se traduzindo em superioridade destas em relação aos três clones de umezeiro. Assim, possivelmente, houve tempo e condições climáticas favoráveis (temperatura e umidade mais elevadas) para que os Clones 10 e 15 se igualassem estatisticamente ao 'Okinawa'.

Neste experimento, verificou-se que o diâmetro dos enxertos (Tabela 3) nos Clones 10 e 15 foi maior do que o observado no 'Okinawa', o que não concorda com Nakamura et al. (1999), nem mesmo com os dados observados no primeiro experimento. Possivelmente, houve limitação do crescimento das raízes em função do longo período mantido nos recipientes (200 dias) durante o verão e, como o 'Okinawa' é vigoroso, pode ter havido limitação do crescimento das raízes e, conseqüentemente, do crescimento em diâmetro do enxerto.

Houve diferença estatística para a porcentagem de pegamento de enxertos (Tabela 3), onde o Clone 05 e 'Okinawa' apresentaram médias superiores aos Clones 10 e 15. Em relação à primeira enxertia, houve aumento considerável na porcentagem de pegamento no Clone 05 (aumentando para 86\%). Possivelmente, a metodologia adotada no segundo experimento, com cortes mais superficiais, auxiliou no pegamento dos enxertos, sobretudo considerando-se o pequeno diâmetro dos porta-enxertos (em torno de $4 \mathrm{~mm}$ ). Entretanto, as porcentagens de pegamento no Clone 15 e 'Okinawa' diminuíram 7\%, aproximadamente, em relação à primeira enxertia, o que pode ser considerado aceitável. Salienta-se, entretanto, que praticamente todos enxertos pegaram quando não houve a morte do porta-enxerto.

Embora tenham sido adotadas metodologias diferentes, e os tempos de avaliações finais diferiram em apenas 20 dias, observam-se valores maiores para o comprimento e diâmetro do enxerto no segundo experimento, em relação ao primeiro. Isso reflete claramente a importância da idade do porta-enxerto no momento da enxertia, especialmente com o 

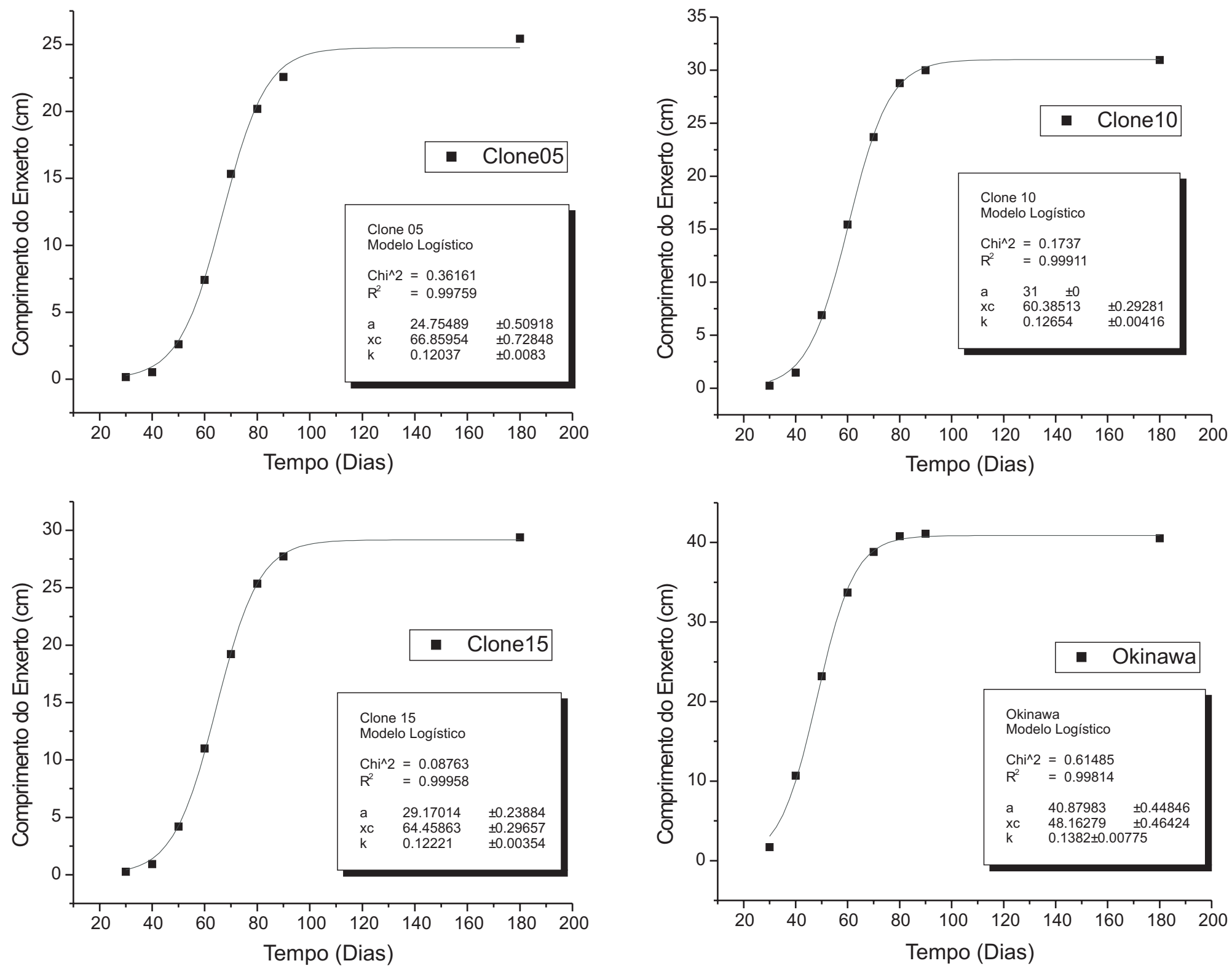

FIGURA 1 - Comprimento do enxerto $(\mathrm{cm})$ da cv. Aurora-1 de pessegueiro em função do número de dias após a enxertia, nos porta-enxertos Clones 05; 10 e 15 de umezeiro e cv. Okinawa, quando adotada a enxertia de borbulhia por escudo, no mês de março. Taquaritinga-SP, setembro de 2002.

TABELA 3 - Comprimento de enxertos ( $\mathrm{cm})$, diâmetro de enxertos a $5 \mathrm{~cm}$ acima do ponto de enxertia (mm), porcentagem de pegamento de enxertos e de porta-enxertos mortos aos 200 dias após a enxertia de borbulhia por escudo modificada (julho), em mudas de pessegueiro cv. Aurora1 sobre diferentes porta-enxertos. Taquaritinga-SP, fevereiro de 2003.

\begin{tabular}{|c|c|c|c|c|}
\hline Porta-enxerto & $\begin{array}{l}\text { Comprimento de enxerto } \\
(\mathrm{cm})\end{array}$ & Diâmetro de enxerto (mm) & $\begin{array}{c}\% \text { de pegamento de } \\
\text { enxertos }\end{array}$ & $\begin{array}{c}\% \text { de porta-enxertos } \\
\text { mortos }\end{array}$ \\
\hline Clone 05 & $80,60 \mathrm{~b}$ & $7,43 \mathrm{bc}$ & $86,0 \mathrm{a}$ & 14,0 bc \\
\hline Clone 10 & $104,30 \mathrm{a}$ & $8,14 \mathrm{ab}$ & $71,0 \mathrm{~b}$ & $28,0 \mathrm{~b}$ \\
\hline Clone 15 & $107,51 \mathrm{a}$ & 8,72 a & $51,0 \mathrm{c}$ & 49,0 a \\
\hline Okinawa & $101,20 \mathrm{a}$ & $7,02 \mathrm{c}$ & 88,0 a & $8,0 \mathrm{c}$ \\
\hline D.M.S. & 13,4346 & 0,8622 & $8,0027^{1}$ & $11,1705^{1}$ \\
\hline $\mathrm{F}$ & $13,41 * *$ & $12,55 * *$ & $32,95 * *$ & $22,57 * *$ \\
\hline $\mathrm{CV}(\%)$ & 7,54 & 6,08 & 7,31 & 22,02 \\
\hline
\end{tabular}

Médias seguidas por letras distintas, na mesma coluna, diferem entre si, pelo teste de Tukey. ${ }^{1}$ diferença mínima significativa obtida para os valores transformados; $* *$ significativo ao nível de $1 \%$ de probabilidade.

estabelecimento adequado do sistema radicular no substrato, trazendo benefícios ao crescimento dos enxertos. Além disso, durante o período após a segunda enxertia, ocorreram temperaturas mais elevadas, o que favoreceu o crescimento dos enxertos.

\section{CONCLUSÕES}

Nas condições em que ambos os experimentos foram realizados, pode-se concluir que:
1. É viável a realização da enxertia do pessegueiro cv. Aurora-1 nos Clones 05; 10 e 15 de umezeiro e no 'Okinawa' propagados por estacas herbáceas, tanto em março quanto em julho, adotando-se a borbulhia por escudo e a borbulhia por escudo modificada.

2. O 'Okinawa' induz maior crescimento dos enxertos da cv. Aurora-1, entretanto não influencia em seu diâmetro, quando a enxertia é realizada em março. Somente o Clone 05 de umezeiro reduz o comprimento dos enxertos em relação ao 'Okinawa', quando a enxertia é realizada em julho. 
3. O 'Okinawa' induz crescimento mais rápido ao enxerto, de forma que o ponto máximo do comprimento é atingido em tempo menor, em relação aos clones de umezeiro.

\section{REFERÊNCIAS}

CAMPO DALL'ORTO, F.A.; OJIMA, M.; BARBOSA, W.; MARTINS, F.P. O nanismo do pessegueiro induzido pela enxertia no damasqueiro-japonês. Pesquisa Agropecuária Brasileira, Brasília, v.27, n.3, p.517-521, 1992.

CAMPO DALL'ORTO, F.A.; BARBOSA, W.; OJIMA, M.; MARTINS, F.P.; FOBÉ, L.A. Comportamento de pessegueiros IAC enxertados no damasqueiro japonês e no pessegueiro 'Okinawa'. In: CONGRESSO BRASILEIRO DE FRUTICULTURA, 13., 1994, Salvador. Anais... Salvador: SBF, v.3, 1994. p.879-880.

FACHINELLO, J.C. Problemática das mudas de plantas frutíferas de caroço. In: SIMPÓSIO INTERNACIONAL DE FRUTAS DE CAROÇO, 1., 2000, Porto Alegre. Anais... Porto Alegre: UFRGS, 2000. p. $25-40$.

HARTMANN, H.T.; KESTER, D.E. Propagación de plantas. 7.ed. México: Compañia Editorial Continental, 1978. 810p.

MALO, S.E. Nature of resistence of Okinawa and Nemaguard peach to the root-knot nematode Meloidogyne javanica. Proceedings of the American Society for Horticultural Science, Alexandria, v.90, p.3946, 1967.

MAYER, N.A.; PEREIRA, F.M.; NACHTIGAL, J.C. Propagação do umezeiro (Prunus mume Sieb \& Zucc.) por estaquia herbácea. Revista Brasileira de Fruticultura, Jaboticabal, v.23, n.03, p.673-676, 2001.

MAYER, N.A.; PEREIRA, F.M.; NACHTIGAL, J.C. Efeito do comprimento de estacas herbáceas de dois clones de umezeiro (Prunus mume
Sieb \& Zucc.) no enraizamento adventício. Revista Brasileira de Fruticultura, Jaboticabal, v.24, n.02, p.500-504, 2002.

MAYER, N.A.; PEREIRA, F.M. Enraizamento de estacas herbáceas de quatro clones de umezeiro (Prunus mume Sieb. et Zucc.) durante o inverno ameno, em Jaboticabal-SP. Revista Brasileira de Fruticultura, Jaboticabal, v.25, n.03, p.505-507, 2003.

MAYER, N.A.; PEREIRA, F.M.; SANTOS, J.M. dos. Reação de clones de umezeiro (Prunus mume Sieb. et Zucc.) e cultivares de pessegueiro a Meloidogyne javanica (Treub, 1885) Chitwood, 1949. Revista Brasileira de Fruticultura, Jaboticabal, v.25, n.01, p.181183, 2003.

MAYER, N.A.; PEREIRA, F.M. Effect of wounds applied to the bases of herbaceous cuttings on the rooting of four japanese apricot clones (Prunus mume Sieb. et Zucc.) in an intermittent mist system. Acta Horticulturae, Wageningen, v.658, p.655-659, 2004.

NACHTIGAL, J.C.; PEREIRA, F.M.; CAMPODALL'ORTO, F.A.; OJIMA, M.; MARTINS, F.P. Propagação vegetativa do umezeiro (Prunus mume) por meio de estacas herbáceas. Revista Brasileira de Fruticultura, Jaboticabal, v.21, n.2, p.226-228, 1999.

NAKAMURA, C.H.; SCARPARE FILHO, J.A.; KLUGE, R.A. Avaliação preliminar do umezeiro como porta-enxerto para pessegueiro e nectarineira. Revista Brasileira de Fruticultura, Jaboticabal, v.21, n.2,p.116-118, 1999.

OJIMA, M.; CAMPO DALL'ORTO, F.A.; BARBOSA, W.; MARTINS, F.P.; SANTOS, R.R. dos. Propagação do pessegueiro: pesquisas no Instituto Agronômico. Campinas: Instituto Agronômico, 1999. 42p. (Documentos IAC, 64).

RASEIRA, M. do C.B.; NAKASU, B.H. Pessegueiro. In: BRUCKNER, C.H. Melhoramento de fruteiras de clima temperado. Viçosa: UFV, 2002.p.89-126. 